\title{
Self-Reported Academic Performance and Lifestyle Habits of School Children in Japan
}

\author{
Jun Kohyama*
}

Tokyo Bay Urayasu Ichikawa Medical Center, 3-4-32 Toudaijima, Urayasu 279-0001, Chiba, Japan

\begin{abstract}
Background and Objective: The purpose of this study was to determine the lifestyle habits significantly associated with self-reported academic performance (AP) in children in grades 5 to 12 in Japan.

Methods: A total of 2,114 completed questionnaires were analyzed. Factors examined included habits related to sleeping, eating, defecation, physical activity, and screen time, in addition to body mass index (BMI). Social jet lag (SJL) was calculated from sleeping factors and categorized into five groups according to its value: minus 1 or less (SJL 1), more than minus 1 and 0 or less (SJL 2), more than 0 and 1 or less (SJL 3), more than 1 and 2 or less (SJL 4), and more than 2 (SJL 5). The association between self-reported AP and other factors except for SJL was assessed by means of multinomial logistic regression analysis.

Results: Factors significantly associated with good self-reported AP included female gender, lower grade, less sleepiness, lower BMI, intake of breakfast, less constipation, early wake-up time during the weekend, and short screen time during the weekend. The mean self-reported AP of SJL 3 was better than that of both SJL 5 and SJL 1.

Conclusions: Self-reported AP was associated with gender, grade, BMI, sleep, breakfast, defecation, and screen time in children in grades 5 to 12 in Japan. It must be ensured that children take enough time to perform the indispensable human behaviors of sleeping, eating, defecation, and physical activity.
\end{abstract}

Keywords: Sleep, breakfast, constipation, social jet lag, physical activity, screen time.

\section{INTRODUCTION}

According to Beebe et al. [1], academic performance (AP) and sleep duration (SD) reveal a true cause and effect relationship. AP is also known to be affected by other lifestyle habits besides sleep, such as regular meal patterns, intake of healthy food items, and physical activity (PA) [2]. Dumuid et al. [3] reported that poor AP has been linked with unhealthy diet, shorter $\mathrm{SD}$, longer screen time, and less PA. Interestingly, short SD is known to cause an increase in body mass index (BMI) [4], which is also associated with basic daily habits of sleeping, eating, and PA [5]. In addition, among schoolchildren in Japan, skipping breakfast, physical inactivity, and late wake up are known to be significantly related to irregular bowel movements, and long TV viewing and late bed time have been reported to be significantly related to non-daily bowel movements [6]. Thus, self-reported AP is hypothesized to be associated with $\mathrm{BMI}$ and defecation habits, in addition to habits related to sleeping, screen time, breakfast intake, and PA.

The author of this article has frequently delivered lectures on sleep, and in cases of lectures for students, students were asked to complete in advance of the lecture a questionnaire on lifestyle habits, including

*Address correspondence to this author at the Tokyo Bay Urayasu Ichikawa Medical Center, 3-4-32 Toudaijima, Urayasu 279-0001, Chiba, Japan; Tel: +81 473513101 ; E-mail: j-kohyama@jadecom.or.jp sleep and self-reported AP, in order to deepen their understanding of sleep. As lifestyle habits are likely to be altered by means of variable social events or trends, the current study used data obtained over eight months between October 2016 and May 2017.

The purpose of this cross-sectional study was to assess the hypothesis that self-reported AP in children in grades 5 to 12 (ages ranging from 10 to 18 years old) in Japan is associated with daily habits of sleeping, screen time, eating, defecation, and PA, as well as BMI. This study was approved by the Committee for Medical Research Ethics of Tokyo Bay Urayasu Ichikawa Medical Center (no. 199). A part of this study has been submitted [7].

\section{MATERIALS AND METHOD}

A questionnaire was delivered to each student by their school teachers between October 2016 and May 2017. A letter was also delivered assuring that their responses would be treated as anonymous and confidential and that it was voluntary to participate. Written consent signed by a parent and filled questionnaires were collected by school teachers on a different day and were sent to the author. Of the 2,704 questionnaires collected from 25 public schools (15 elementary schools (ES), 7 junior high schools (JHS) and 3 high schools (HS)), 2,114 agreed to participate in the study and had answered all the required questions. In these 25 schools studied, school start time ranged 
from $8: 35$ to $8: 45$ in ES, from $8: 10$ to $8: 25$ in JHS, and from $8: 35$ to $8: 40$ in $\mathrm{HS}$, and end time from $15: 10$ to $15: 45$ in ES, from $15: 45$ to $16: 05$ in JHS, and from $15: 40$ to $16: 10$ in $\mathrm{HS}$.

The questionnaires included questions about school grade (from 5 to 12), gender (1. male, 2. female), body weight and height to calculate BMI, frequency of taking breakfast (BF: 1. always, 2. often, 3. sometimes, 4. never), defecation (DF: 1 . every day, 2 . every other day, 3. once every two to three days, 4 . twice a week, 5. once a week, 6. more than a week interval), PA (0. none, 1 . one day per week, 2 . two days per week, 3 . three days per week, 4. four days per week, 5. five days per week, 6 . six days per week, 7 . seven days per week), screen time during weekdays (WdScT) and weekends (WeScT) $(1 .<2$ hours, 2. 2-4 hours, 3. 4-6 hours, 4. 6-8 hours, 5. 8 hours $=</$ day), and selfreported AP (1. good, 2. relatively good, 3. relatively poor, 4. poor).

Although Beebe et al. [1] and Dumuid et al. [3] focused on SD among sleep elements in relation to AP, both long sleep and short sleep have been recognized as sleep disorders [8]. SD might be insufficient to represent sleep elements assessing relationships with AP. Thus, in the current questionnaire, bed time on weekdays (WdBT) and weekends (WeBT) (1. <8PM, 2. $8 \mathrm{PM}=<<9 \mathrm{PM}, 3$. 9PM $=<<10 \mathrm{PM}, 4$. 10PM $=<<11 \mathrm{PM}, 5$. $11 \mathrm{PM}=<<0 \mathrm{AM}, 6.0 \mathrm{AM}=<<1 \mathrm{AM}, 7.1 \mathrm{AM}=<<2 \mathrm{AM}, 8$. $2 A M=<<3 A M, 9.3 A M=<$ ) and wake-up time (1. $<5 A M$, 2. $5 \mathrm{AM}=<<6 \mathrm{AM}, 3.6 \mathrm{AM}=<<7 \mathrm{AM}, 4.7 \mathrm{AM}=<<8 \mathrm{AM}, 5$. $8 \mathrm{AM}=<<9 \mathrm{AM}, 6.9 \mathrm{AM}=<<10 \mathrm{AM}, 7.10 \mathrm{AM}=<<11 \mathrm{AM}, 8$. $11 \mathrm{AM}=<<0 \mathrm{PM}, 9.0 \mathrm{PM}=<$ ) on weekdays $(\mathrm{WdAwT})$ and weekends (WeAwT) were also ascertained. Regarding bed time and wake-up time, representative times for each category were determined as follows: 7:30PM, 8:30PM, 9:30PM, 10:30PM, 11:30PM, 0:30AM, $1: 30 \mathrm{AM}$, and 2:30AM for bed time, and 4:30AM, 5:30AM, 6:30AM, 7:30AM, 8:30AM, 9:30AM, 10:30AM, 11:30AM, and 12:30PM for wake-up time, respectively. Sleep duration on weekdays (WdSD) and weekends (WeSD) and social jet lag (SJL; the difference of the mid-point time of sleep between weekend and weekday) [9] were calculated from these data. SJL was categorized into five groups according to their distribution: -1 or less (SJL 1), more than -1 and 0 or less (SJL 2), more than 0 and 1 or less (SJL 3), more than 1 and 2 or less (SJL 4), and more than 2 (SJL 5). For screen time, representative values for each category were determined as follows: 1 hour, 3 hours, 5 hours, 7 hours, and 9 hours, respectively.
In addition, since sleepiness during class is one of the most frequent complaints of schoolchildren at my sleep clinic [10], in the present questionnaire, the frequency of students who felt sleepy during class (SI: 1. never, 2. sometimes, 3. often, 4. always) was ascertained. The rate of poor self-reported AP (rated more than 2 on AP), poor breakfast takers (rated more than 2 on BF), constipation (rated 4 or more on DF, according to the standard criteria [11]), sleepiness (rated more than 2 on $\mathrm{SI}$ ), poor (rated 0 on PA) and heavy (rated 7 on PA) PA, and heavy screen watchers (rated 3 or more on ScT) were also calculated. To determine the association among each factor obtained, a correlation matrix among all obtained factors was produced, in addition to correlation coefficients between grade and each factor.

The association between self-reported AP and other factors was assessed by means of multinomial logistic regression analysis. Since WdSD, WeSD, and SJL were obtained from WdBT, WeBT, WdAwT, and WeAwT, these three factors were not included in the explanatory variables. ANOVA was used to determine the differences between factors including self-reported AP and each SJL group. Student's t test was used to assess the significance of correlation coefficients, the difference of factors between SJL1 and SJL 3, and also between SJL 3 and SJL 5, respectively. A p value of $<0.05$ was considered statistically significant. These analyses were conducted by means of Bell Curve for Excel (SSRI).

\section{RESULTS}

\section{Basic Data on each Factor}

Averages and standard deviations of the main variables are shown in Tables 1 to 3 .

Bed times were delayed significantly with grade progression (Table 1). Awake times on weekdays showed no significant grade-related changes, but those on the weekend delayed significantly with grade progression (Table 1). SDs were shortened significantly with grade progression (Table 1). The mean SJLs ranged from 0.6 (elementary school male [ESM]) to 1.0 (both junior high school and high school female (JHSF and $\mathrm{HSF})$ ), and were increased significantly with grade progression (Table 1).

Although BMI revealed significant grade-related elevation (Table 2), these mean BMI values were consistent with the standard values for schoolchildren 
Table 1: Data on Sleep Measures

\begin{tabular}{|c|c|c|c|c|c|c|c|c|}
\hline \multirow[b]{2}{*}{ Grade } & \multirow[b]{2}{*}{ Gender/N } & WdBT & WeBT & WdAwT & WeAwT & WdSD & WeSD & SJL \\
\hline & & $\begin{array}{l}\text { Mean (time), } \\
\text { SD (hr) }\end{array}$ & $\begin{array}{c}\text { Mean (time), } \\
\text { SD (hr) }\end{array}$ & $\begin{array}{c}\text { Mean (time), } \\
\text { SD (hr) }\end{array}$ & $\begin{array}{l}\text { Mean (time), } \\
\text { SD (hr) }\end{array}$ & $\begin{array}{c}\text { Mean (hr), } \\
\text { SD (hr) }\end{array}$ & $\begin{array}{l}\text { Mean (hr), } \\
\text { SD (hr) }\end{array}$ & $\begin{array}{c}\text { Mean (hr), } \\
\text { SD (hr) }\end{array}$ \\
\hline \multirow[t]{2}{*}{ 5-6, ES } & $\mathrm{M} / 445$ & $21: 53,0.8$ & $22: 13,1.0$ & $6: 29,0.5$ & $7: 17,1.1$ & $8.6,0.8$ & $9.1,1.1$ & $0.6,0.7$ \\
\hline & $\mathrm{F} / 517$ & $21: 56,0.8$ & $22: 17,0.9$ & $6: 29,0.4$ & $7: 52,1.1$ & $8.5,0.8$ & $9.6,1.0$ & $0.9,0.7$ \\
\hline \multirow[t]{2}{*}{ 7-9, JHS } & $\mathrm{M} / 450$ & $23: 00,1.3$ & $23: 23,1.4$ & $6: 33,0.7$ & $7: 53,1.6$ & $7.5,1.2$ & $8.5,1.5$ & $0.9,0.9$ \\
\hline & $\mathrm{F} / 417$ & $23: 10,1.0$ & $23: 28,1.2$ & $6: 29,0.7$ & $8: 12,1.4$ & $7.3,1.0$ & $8.7,1.2$ & $1.0,0.8$ \\
\hline \multirow[t]{2}{*}{$10-12, \mathrm{HS}$} & $\mathrm{M} / 187$ & $23: 51,0.9$ & $0: 02,1.0$ & $6: 24,0.8$ & $7: 59,1.6$ & $6.6,1.0$ & $7.9,1.4$ & $0.9,0.9$ \\
\hline & $F / 98$ & $23: 43,1.0$ & $0: 02,1.1$ & $6: 19,0.8$ & $7: 56,1.6$ & $6.6,1.0$ & $7.9,1.4$ & $1.0,0.8$ \\
\hline \multicolumn{9}{|c|}{ Correlation coefficient between grade } \\
\hline & M & 0.62 & 0.55 & 0.03 (NS) & 0.23 & -0.62 & -0.31 & 0.17 \\
\hline & $\mathrm{F}$ & 0.61 & 0.55 & -0.02 (NS) & 0.09 & -0.62 & -0.45 & 0.08 \\
\hline & Total & 0.62 & 0.55 & $0.01(\mathrm{NS})$ & 0.15 & -0.62 & -0.38 & 0.12 \\
\hline
\end{tabular}

ES: elementary school, JHS: junior high school, HS: high school, M: male, F: female, SD: standard deviation, WdBT: weekday bed time, WeBT: weekend bed time, WdAwT: weekday awake time, WeAwT: weekend awake time, WdSD: weekday sleep duration, WeSD: weekend sleep duration.

NS: not significant.

in Japan [12]: grade 5: male 17.7 (SD 3.1), female 17.3 (2.6); grade 6: male 18.2 (3.0), female 18.0 (2.8); grade 7: male 19.1 (3.3), female 18.9 (2.9); grade 8: male 19.2 (3.0), female 19.8 (3.0); grade 9: male 20.0 (3.1), female 20.6 (2.8); grade 10: male 20.5 (3.0), female 21.0 (3.0); grade 11: male 21.1 (3.3), female 20.8 (2.8); grade 12: male 21.7 (3.5), female $21.6(3.4)$.

Frequencies of students who felt sleepy during class increased significantly with grade progression, and more than $30 \%$ of high school students in the present analysis were found to feel sleepy during class
(Table 2). Breakfast skippers comprised less than $5 \%$ in the present analysis, and grade-related increases were not found among male students (Table 2). A grade-related increase of constipation was found among female students, and its rates distributed from $8.6 \%$ (high school male [HSM]) to $29.5 \%$ (JHSF) (Table 2).

A grade-related increase of PA was found among male students (Table 3). Students who were not engaged in PA distributed from $16.6 \%$ (ESM) to $49.0 \%$ (HSF), and those involved in PA seven days a week

Table 2: Data on BMI, Sleepiness, Breakfast and Defecation

\begin{tabular}{|c|c|c|c|c|c|}
\hline \multirow[b]{2}{*}{ Grade } & \multirow{2}{*}{ Gender/N } & BMI & SI & BF & DF \\
\hline & & Mean, SD & $\begin{array}{c}\text { Mean, SD, } \\
\% \text { of sleepiness }\end{array}$ & $\begin{array}{c}\text { Mean, SD, } \\
\% \text { of poor breakfast takers }\end{array}$ & $\begin{array}{c}\text { Mean, SD, } \\
\% \text { of constipation }\end{array}$ \\
\hline \multirow[t]{2}{*}{$5-6$, ES } & $\mathrm{M} / 445$ & $18.2,3.0$ & $1.6,0.7,7.0 \%$ & $1.1,0.4,2.2 \%$ & $1.4,0.8,11.7 \%$ \\
\hline & $\mathrm{F} / 517$ & $17.8,2.7$ & $1.6,0.6,5.8 \%$ & $1.1,0.3,1.2 \%$ & $1.7,0.9,19.7 \%$ \\
\hline \multirow[t]{2}{*}{ 7-9, JHS } & $\mathrm{M} / 450$ & $19.6,3.1$ & $2.0,0.8,19.8 \%$ & $1.2,0.6,4.7 \%$ & $1.6,0.9,16.9 \%$ \\
\hline & $\mathrm{F} / 417$ & $19.4,2.5$ & $2.0,0.7,16.5 \%$ & $1.2,0.6,4.6 \%$ & $2.0,1.1,29.5 \%$ \\
\hline \multirow[t]{2}{*}{$10-12, \mathrm{HS}$} & $\mathrm{M} / 187$ & $20.2,2.5$ & $2.3,0.8,32.6 \%$ & $1.1,0.5,4.3 \%$ & $1.4,0.7,8.6 \%$ \\
\hline & $\mathrm{F} / 98$ & $20.1,1.9$ & $2.5,0.8,43.9 \%$ & $1.2,0.5,4.1 \%$ & $1.7,1.1,20.4 \%$ \\
\hline \multicolumn{6}{|c|}{ Correlation coefficient between grade } \\
\hline & M & 0.28 & 0.34 & 0.06 (NS) & 0.00 (NS) \\
\hline & $\mathrm{F}$ & 0.34 & 0.38 & 0.13 & 0.08 \\
\hline & Total & 0.31 & 0.36 & 0.09 & 0.02 (NS) \\
\hline
\end{tabular}

ES: elementary school, JHS: junior high school, HS: high school, M: male, F: female, SD: standard deviation, BMI: body mass index, SI: sleepiness, BF: breakfast, DF: defecation. NS: not significant. 
Table 3: Data on Physical Activity, Screen Time and Self-Reported Academic Performance

\begin{tabular}{|c|c|c|c|c|c|}
\hline Grade & Gender/N & PA (days) & WdScT & WeScT & Self-reported AP \\
\hline & & $\begin{array}{c}\text { Mean, SD, } \\
\% \text { of no PA, } \\
\% \text { of PS } 7 \text { days a week }\end{array}$ & $\begin{array}{c}\text { Mean }(\mathrm{hr}), \mathrm{SD}(\mathrm{hr}), \% \text { of } \\
\text { hard screen watchers on } \\
\text { weekdays }\end{array}$ & $\begin{array}{l}\text { Mean }(\mathrm{hr}), \mathrm{SD}(\mathrm{hr}), \% \text { of hard } \\
\text { screen watchers on weekend }\end{array}$ & $\begin{array}{c}\text { Mean, SD, \% of } \\
\text { poor self-reported AP }\end{array}$ \\
\hline \multirow[t]{2}{*}{$5-6$, ES } & $\mathrm{M} / 445$ & $3.3,2.6,16.6 \%, 24.9 \%$ & $4.0,1.4,7.4 \%$ & $5.4,2.0 .31 .5 \%$ & $2.2,0.7,33.0 \%$ \\
\hline & $\mathrm{F} / 517$ & $1.9,2.2,35.6 \%, 9.3 \%$ & $4.0,1.3,7.4 \%$ & $5.4,1.8,29.6 \%$ & $2.1,0.7,25.7 \%$ \\
\hline \multirow[t]{2}{*}{ 7-9, JHS } & $\mathrm{M} / 450$ & $4.2,2.8,21.1 \%, 36.7 \%$ & $4.4,1.7,11.3 \%$ & $6.0 .2 .3,42.0 \%$ & $2.6,0.9,56.2 \%$ \\
\hline & $\mathrm{F} / 417$ & $3.0,3.0,39.6 \%, 24.0 \%$ & $4.1,1.6,5.8 \%$ & $5.6,2.2,32.1 \%$ & $2.6,0.8,52.0 \%$ \\
\hline \multirow[t]{2}{*}{ 10-12, HS } & $\mathrm{M} / 187$ & $4.1,3.0,29.4 \%, 36,4 \%$ & $4.5,1.5,13.9 \%$ & $5.5,1.9,33.2 \%$ & $2.6,0.9,52.4 \%$ \\
\hline & $\mathrm{F} / 98$ & $2.4,2.9,49.0 \%, 19.6 \%$ & $4.8,1.7,19.4 \%$ & $6.4,2.2,43.9 \%$ & $2.6,0.8,52.0 \%$ \\
\hline \multicolumn{6}{|c|}{ Correlation coefficient between grade } \\
\hline & M & 0.07 & 0.13 & 0.05 (NS) & 0.19 \\
\hline & $\mathrm{F}$ & 0.03 (NS) & 0.11 & 0.05 (NS) & 0.26 \\
\hline & Total & 0.07 & 0.13 & 0.06 & 0.23 \\
\hline
\end{tabular}

ES: elementary school, JHS: junior high school, HS: high school, M: male, F: female, SD: standard deviation, PA: physical activity, WdScT: weekday screen time, WeScT: weekend screen time, AP: academic performance.

NS: not significant.

ranged from $9.3 \%$ (elementary school female $[E S F]$ ) to $36.7 \%$ (junior high school male [JHSM]). Screen times increased with grade progression when analyzing both genders together (Table 3 ). It should be noted that the differences in averaged screen times between weekdays and weekends distributed from 1.0 hour (HSM) to 1.6 hours (JHSM and HSF) (Table 3). Selfreported AP values showed grade-related increases, indicating the grade-related increase of students with poor self-reported AP (Table 3). Table 4 shows the correlation matrix among the data obtained.

\section{Factors Associated with Self-Reported AP}

Factors significantly associated with better selfreported AP included female gender (odds ratio [OR]: $1.35 ; 95 \%$ confidence interval [Cl]: 1.11, 1.64; $\mathrm{p}=0.0023$ ), lower grade (OR: $1.18 ; 95 \% \mathrm{Cl}: 1.10,1.26$; $\mathrm{p}<0.001$ ), less sleepiness (OR: $1.30 ; 95 \% \mathrm{Cl}: 1.14$, $1.47 ; p<0.001$ ), lower BMI (OR: $1.07 ; 95 \% \mathrm{Cl}: 1.03$, $1.10 ; p<0.001$ ), better breakfast intake (OR: 1.80; $95 \%$ Cl: $1.45,2.24 ; p<0.001$ ), less constipation (OR: 1.17; $95 \% \mathrm{Cl}: 1.06,1.30 ; \mathrm{p}=0.0022)$, earlier WeAwT (OR:

Table 4: Correlation Matrix

\begin{tabular}{|c|c|c|c|c|c|c|c|c|c|c|c|c|c|}
\hline & $\begin{array}{c}\text { Gender (M(1) or } \\
F(2))\end{array}$ & BMI & WdBT & WeBT & WdAwT & WeAwT & SI & BF & DF & PA & WdScT & WeScT & SRAP \\
\hline Grade & -0.1085 & 0.3113 & 0.6161 & 0.5535 & 0.0090 & 0.1528 & 0.3585 & 0.0894 & 0.0202 & 0.0739 & 0.1264 & 0.0570 & 0.2309 \\
\hline$M(1)$ or $F(2)$ & 1.0000 & -0.0743 & -0.0386 & -0.0315 & -0.0251 & 0.1308 & -0.0129 & -0.0091 & 0.1711 & -0.2452 & -0.0347 & -0.0414 & -0.0779 \\
\hline BMI & & 1.0000 & 0.1954 & 0.2217 & -0.0388 & 0.0606 & 0.1373 & 0.0866 & -0.0315 & 0.0151 & 0.1092 & 0.1411 & 0.1726 \\
\hline WdBT & & & 1.0000 & 0.8441 & 0.2704 & 0.3976 & 0.3354 & 0.2056 & 0.0906 & -0.0589 & 0.2382 & 0.1570 & 0.1927 \\
\hline WeBT & & & & 1.0000 & 0.2525 & 0.5012 & 0.3362 & 0.2320 & 0.1080 & -0.0779 & 0.2684 & 0.2468 & 0.2217 \\
\hline WdAwT & & & & & 1.0000 & 0.4415 & 0.0295 & 0.1311 & 0.0523 & -0.1496 & 0.0464 & 0.0145 & 0.0772 \\
\hline WeAwT & & & & & & 1.0000 & 0.1528 & 0.1710 & 0.0865 & -0.2576 & 0.1602 & 0.2192 & 0.1502 \\
\hline SI & & & & & & & 1.0000 & 0.1551 & 0.0633 & 0.0288 & 0.1886 & 0.1668 & 0.1990 \\
\hline $\mathrm{BF}$ & & & & & & & & 1.0000 & 0.1584 & -0.0812 & 0.2140 & 0.1847 & 0.2008 \\
\hline DF & & & & & & & & & 1.0000 & -0.1301 & 0.1159 & 0.0939 & 0.0957 \\
\hline PA & & & & & & & & & & 1.0000 & -0.0543 & -0.0912 & -0.0344 \\
\hline WdScT & & & & & & & & & & & 1.0000 & 0.7198 & 0.1544 \\
\hline WeScT & & & & & & & & & & & & 1.0000 & 0.1616 \\
\hline SRAP & & & & & & & & & & & & & 1.0000 \\
\hline
\end{tabular}

Statistically significant correlation coefficients are expressed in bold numbers.

M: male, F: female, BMI: body mass index, WdBT: weekday bed time, WeBT: weekend bed time, WdAwT: weekday awake time, WeAwT: weekend awake time, SI: sleepiness, BF: breakfast, DF: defecation, PA: physical activity, WdScT: weekday screen time, WeScT: weekend screen time, SRAP: self-reported academic performance. 
1.13; $95 \% \mathrm{Cl}: 1.03,1.23 ; \mathrm{p}=0.0068)$, and shorter WeScT (OR: $1.14 ; 95 \%$ Cl: $1.00,1.30 ; p=0.0469$ ).

\section{Social Jet Lag}

The numbers of students categorized into the five SJL groups were as follows: SJL 1, $n=19$; SJL 2, $\mathrm{n}=452$; SJL 3, n=1082; SJL 4, n=459; SJL 5, n=102. The percentages of SJL1 and 5 in each grade/gender group were as follows: ESM (SJL 1, 0.7\%; SJL5, 2.0\%), ESF (SJL 1, 2.1\%; SJL5, 5.6\%), JHSM (SJL 1, $0.2 \%$; SJL5, 3.3\%), JHSF (SJL 1, 0.2\%; SJL5, 3.4\%), HSM (SJL 1, 1.1\%; SJL5, 15.0\%), HSF (SJL 1, 1.0\%; SJL5, 7.1\%). ANOVA revealed that all factors including self-reported AP were significantly different among SJL 1 to 5. The mean self-reported AP of SJL 3 was significantly lower (better) than that of both SJL 5 and SJL 1 (Figure 1). For the other factors, in comparison with SJL 3 students, SJL 5 students were significantly higher in grade $(p<0.001)$ and had a longer WeSD $(p<0.001)$, a shorter WdSD $(p<0.001)$, a longer WdScT $(p<0.001)$ and WeScT $(p<0.001)$, a later WdBT $(p<0.001)$ and WeBT $(p<0.001)$, a later WeAwT $(p<0.001)$, more constipation $(p<0.02)$, sleepiness $(p<0.001)$, poorer breakfast intake $(p<0.001)$, and a higher BMI $(p<0.001)$. Compared with SJL 3 students, SJL 1 students showed a significantly higher male rate $(p<0.001)$ and had a shorter WeSD $(p<0.002)$, a shorter WeScT $(p<0.001)$, an earlier WeBT $(p<0.001)$,

\section{Self-reported AP (mean, standard error)}

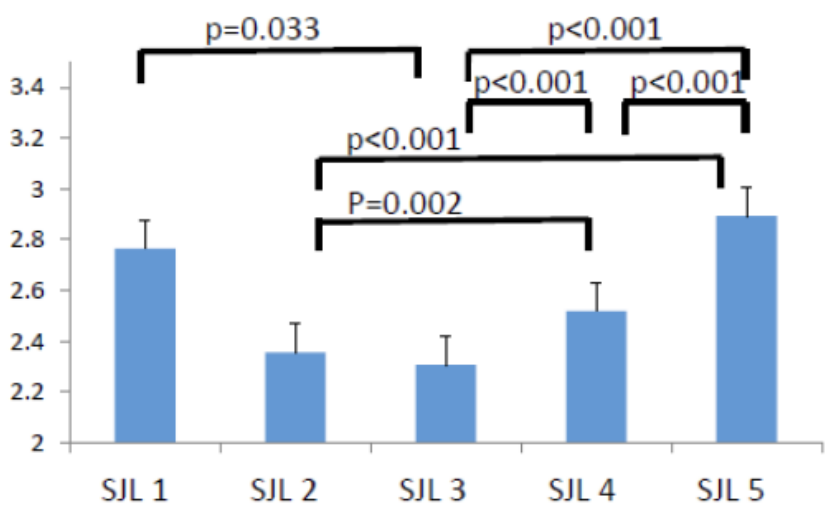

Figure 1: Self-reported academic performance and social jet lag.

SJL was categorized into five groups according to their distribution: -1 or less (SJL 1, $n=19$ ), more than -1 and 0 or less (SJL 2, $n=452$ ), more than 0 and 1 or less (SJL 3, $\mathrm{n}=1082$ ), more than 1 and 2 or less (SJL $4, \mathrm{n}=459$ ), more than 2 (SJL 5, n=102). ANOVA revealed that self-reported AP was significantly different among SJL 1 to 5 , and a t test revealed significant differences of self-reported AP values between the SJL 3 group and both the SJL 1 and SJL 5 groups. AP, academic performance; SJL, social jet lag; N, number. a later WdAwT $(p<0.001)$, an earlier WeAwT, and more PA $(p<0.02)$.

\section{DISCUSSION}

Regarding the validity of self-reported AP, although its limitations have recently been indicated [13], selfreported grades and scores are generally taken to be accurate [14] and are widely used as measures of student performance in studies of educational outcomes and interventions [15-17]. Therefore, in the current study, self-reported AP was used as a significant measure.

In the present study, better self-reported AP was associated with female gender. For more than 100 years, girls have been found to perform better than boys in reading and spelling [18, 19], and boys in mathematical areas [20, 21]. Recently, based on the Programme for International Student Assessment conducted by the Organization for Economic Cooperation and Development, Stoet and Geary [22] concluded that girls' overall achievement (across mathematics, reading, and science) exceeds that of boys'. The current results are consistent with this report.

The current study demonstrated that the higher the grade, the poorer the self-reported AP. Self-reported AP is affected by students' character [13]. Self-esteem, one of the personality characteristics, is known to be high in young children but to decline over the course of childhood into adolescence [23]. Thus, self-reported AP might decline with age progression during childhood and adolescence. This age-related assumption is consistent with the present grade-related increase of students with poor self-reported AP.

Although the variability of the length of sleep from person to person and from night to night is quite high [24], the mean WdSD of the present students was shorter than the recommendation of the Centers for Disease Control and Prevention [25] (6-12 years old, 9-12 hours; $13-18$ years old, 8-10 hours), although the mean WeSD of ES and JHS students exceeded the shorter recommendation levels of 9 hours and 8 hours, respectively. It is obvious that the total weekly SD of our students did not reach the shorter recommended level. It is assumed that they are at risk for sleep shortage. Insufficient sleep causes various brain dysfunctions in both adults and children [26]. It is also associated with behavioral, cognitive, and physical problems [27-29], as well as obesity through not only 
hormonal alterations [4] but also a decrease in the activity of the human frontal cortex, combined with a converse amplification of activity within the amygdala [30]. Sleep loss is also known to decrease activity of the prefrontal cortex [31]. Sleep shortage is assumed to be associated with functional brain alteration. Insufficient sleep-induced obesity could result in the occurrence of metabolic syndrome, even in children [32]. Consistent with my hypothesis, the present study showed that self-reported AP is associated with BMI: the higher the BMI, the poorer the self-reported AP. Similarly, poorer self-reported AP was found to be associated with more constipation, more skipping breakfast, and longer WeScT.

Although longer $\mathrm{WeScT}$, presumably reflecting sedentary behavior, was associated with poorer selfreported AP, PA showed no significant association with self-reported AP, in contrast to former reports [1-3]. Interestingly, more than $20 \%$ of the total students who responded were found to be implicated in PA seven days a week (Table 3). I am afraid that the advantage of PA has been emphasized too much, resulting in failure to secure enough SD.

Urrila et al. [33] reported that a shorter time in bed during weekdays and longer weekend sleeping hours correlate with smaller brain gray matter volumes in the frontal, anterior cingulate, and precuneus cortex regions. According to Taki et al. [34], the regional gray matter volume of the bilateral hippocampal body was significantly positively correlated with WdSD. Sleep shortage during weekday are assumed to be associated with morphological brain alteration. Indeed, the present study demonstrated a significant association between earlier WeAwT and better selfreported AP. Interestingly, the Ministry of Education, Culture, Sports, Science and Technology of Japan [35] reported that more than two hours' difference in wakeup time on a holiday and a weekday is associated with poor AP. Needless to say, AP obviously reflects a sort of brain activity that is assumed to be affected by morphological change. It could be assumed that late WeAwT might reflect sleep shortage on weekdays and might produce poor AP through functional brain deficit.

In the current study, more than a quarter $(26.5 \%$ (561/2114)) of whole students were categorized into SJL 4 and 5, who had a SJL of more than 1 hours. SJL [9] has been paid attention recently and is known to be associated with variable problems [36-39], especially among those who had a SJL of more than 1 hour [37]. Consistently, the current study revealed that the mean self-reported AP of SJL 3 was better than that of SJL 4 and 5 (Figure 1). In comparison with SJL 3 students, SJL 5 students were found to have a longer screen time, a later bed time, and a shorter WdSD, resulting in a later WeAwT with a longer WeSD. A later bed time might also be affected by attending preparatory schools or variable types of club activities after school, although the present study failed to obtain data on it. It is difficult to determine that the high positive SJL values were due to a voluntary late bed time (= increase of screen time, etc) or to an involuntary/forced late bed time (= increase of duties). However, I would like to emphasize again that not only the self-reported AP of SJL 3 but also breakfast and bowel habits of SJL 3 were better than that of SJL 5 .

In addition, the mean self-reported AP of SJL 3 was better than that of SJL 1. To my knowledge, few descriptions have been made on negative SJL values. Interestingly, SJL 1 students had a higher PA value than SJL 3 students. SJL 1 students in the present study might be forced to wake up early in the weekend morning to practice PA, resulting in suffering from sleep loss and poor self-reported AP.

No objective AP data were available in the current study. This is one of the limitations of the present study. However, it is worth noting that unfavorable selfreported AP, which reflects a sort of brain activity, was significantly associated with various lifestyle habits, such as skipping breakfast, constipation, and long screen time during the weekend, in addition to male gender, higher grade, sleepiness, and higher BMI. Sleepiness and higher BMI could be taken as results of daily lifestyle habits, and long screen time is assumed as a sedentary behavior. Thus, the current results could be interpreted that brain activity assessed by self-reported AP was affected by a broad area of lifestyle habits of essentially required human behaviors, such as sleeping, eating, defecation, and exercise (PA). Sleeping, eating, defecation, and PA are essential human behaviors accompanied by pleasant feelings. The association of pleasant feelings with these behaviors might suggest that these behaviors are essentially important for the life of human beings. The current study may reveal that these indispensable human behaviors are associated with brain activity, assessed by self-reported AP. To improve AP and properly activate brain activity, we should ensure that children perform the indispensable human behaviors of sleeping, eating, defecation, and PA.

\section{CONCLUSION}

Self-reported AP was associated with BMI, sleep, breakfast, defecation, screen time, and PA in children 
in grades 5 to 12 in Japan. We should ensure that children take enough time to perform the indispensable human behaviors of sleeping, eating, defecation, and PA.

\section{REFERENCES}

[1] Beebe DW, Field J, Miller MM, Miller LE, Le Blond E. Impact of multi-night experimentally induced short sleep on adolescent performance in a simulated classroom. Sleep; in press. https://doi.org/10.1093/sleep/zsw035

[2] Stea TH, Knutsen T, Torstveit MK. Association between short time in bed, health-risk behaviors and poor academic achievement among Norwegian adolescents. Sleep Med 2014; 15: 666-71. https://doi.org/10.1016/j.sleep.2014.01.019

[3] Dumuid D, Olds T, Martín-Fernández JA, Lewis LK, Cassidy $\mathrm{L}$, Maher $\mathrm{C}$. Academic performance and lifestyle behaviors in Australian school children: a cluster analysis. Health Educ Behav; in press

[4] Taheri S. The link between short sleep duration and obesity: we should recommend more sleep to prevent obesity. Arch Dis Child 2006; 91: 881-4. https://doi.org/10.1136/adc.2005.093013

[5] Tovar A, Chui K, Hyatt RR, et al. Healthy lifestyle behaviors associated with overweight and obesity in US rural children. BMC Pediatr 2012; 12: 102. https://doi.org/10.1186/1471-2431-12-102

[6] Yamada M, Sekine $M$, Tatsuse T. Lifestyle and bowel movements in school children: results from the Toyama Birth Cohort Study. Pediatr Int 2017; 59: 604-13. https://doi.org/10.1111/ped.13206

[7] Kohyama J. Self-reported academic performance and lifestyle habits of school children in Japan:a preliminary cross-sectional study. Exploratory Research and Hypothesis in Medicine; under submission

[8] American Academy of Sleep Medicine. The international classification of sleep disorders. 3rd ed. Westchester: American Academy of Sleep Medicine; 2014.

[9] Wittmann M, Dinich J, Merrow M, Roenneberg T. Social jet lag: misalignment of biological and social time. Chronobiol Int 2006; 23: 497-509.

https://doi.org/10.1080/07420520500545979

[10] Kohyama J, Anzai Y, Ono M, et al. Pediatric patients who visited a sleep clinic in a general hospital (in Japanese). Nihon Shounika Gakkai Zasshi 2017; 121: 256.

[11] Shih DQ, Kwan LY. All roads lead to Rome: Update on Rome III Criteria and new treatment options. Gastroenterol Rep 2007; 1: 56-65.

[12] Japan Society of School Health. Annual reports on health of children attending elementary schools and junior high schools in 2014. Tokyo: Japan Society of School Health; 2016.

[13] Rosen JA, Porter SR, Rogers J. Understanding student selfreports of academic performance and course-taking behavior. AERA Open 2017; 3: 1-14. https://doi.org/10.1177/2332858417711427

[14] Kuncel NR, Crede M, Thomas LL. The validity of selfreported grade point averages, class ranks, and test scores: A meta-analysis and review of the literature. Rev Educ Res 2005; 75: 63-82. https://doi.org/10.3102/00346543075001063

[15] Ratelle CF, Duchesne S. Trajectories of psychological need satisfaction from early to late adolescence as a predictor of adjustment in school. Contemp Educ Psych 2014; 39: 388400.

https://doi.org/10.1016/j.cedpsych.2014.09.003
[16] Guo J, Marsh HW, Morin AJS, Parker PD, Kaur G. Directionality of the associations of high school expectancy value, aspirations, and attainment: A longitudinal study. Am Educ Res J 2015; 52: 371-402.

https://doi.org/10.3102/0002831214565786

[17] Yeager DS, Romero C, Paunesku D, et al. Using design thinking to make psychological interventions ready for scaling: The case of the growth mindset during the transition to high school. J Educ Psychol 2016; 108: 374-91. https://doi.org/10.1037/edu0000098

[18] Burt C, Moore RC. The mental differences between the sexes J Exp Pedagogy 1912; 273-84: 355-88.

[19] Halpen DF. Sex differences in cognitive abilities. 4th ed. New York: Psychology Press; 2012.

[20] Stockard LV, Bell JC. A preliminary study of the measuring of abilities in geometry. J Educ Psychol 1916; 7: 567-80. https://doi.org/10.1037/h0069838

[21] Geary DC. Sexual selection and sex differences in mathematical abilities. Behav Brain Sci 1996; 19: 229-47. https://doi.org/10.1017/S0140525X00042400

[22] Stoet G, Geary DC. Sex differences in academic achievement are not related to political, economic, or social equality. Intelligence $2015 ; 48: 137-51$ https://doi.org/10.1016/j.intell.2014.11.006

[23] Robins RW, Trzesniewski KH. Self-esteem development across the lifespan. Curr Direc Psychol Sci 2005; 14: 158-62. https://doi.org/10.1111/j.0963-7214.2005.00353.x

[24] Carskadon M, Dement WC. Normal human sleep: an overview. In: Principles and practice of sleep medicine. 6th ed. Elsevier 2017; pp. 15-24 https://doi.org/10.1016/B978-0-323-24288-2.00002-7

[25] Centers for Disease Control and Prevention. Sleep>Basics about sleep> How much sleep do I need? [cited 2017 July 24]. Available from: https://www.cdc.gov/sleep/about_sleep/ how_much_sleep.html

[26] Mindell JA, Owens J, Alves R, et al. Give children and adolescents the gift of a good night's sleep: a call to action. Sleep Med 2011; 12: 203-4. https://doi.org/10.1016/j.sleep.2011.01.003

[27] Schlarb AA, Sopp R, Ambiel D, Grünwald J. Chronotyperelated differences in childhood and adolescent aggression and antisocial behavior: a review of the literature. Chronobio Int 2014; 31: 1-16. https://doi.org/10.3109/07420528.2013.829846

[28] Yokomaku A, Misao K, Omoto $\mathrm{F}$, et al. A study of the association between sleep habits and problematic behaviors in preschool children. Chronobiol Int 2008; 25: 549-64. https://doi.org/10.1080/07420520802261705

[29] Osonoi Y, Mita, T, Osonoi T, et al. Morningness-eveningness questionnaire score and metabolic parameters in patients with type 2 diabetes mellitus. Chronobiol Int 2014; 31: 101723.

https://doi.org/10.3109/07420528.2014.943843

[30] Greer SM, Goldstein AN, Walker MP. The impact of sleep deprivation on food desire in the human brain. Nat Commun 2013; 4: 2259. https://doi.org/10.1038/ncomms3259

[31] Ma N, Dinges DF, Basner M, Rao H. How acute total sleep loss affects the attending brain: a meta-analysis of neuroimaging studies. Sleep 2015; 38: 233-40. https://doi.org/10.5665/sleep.4404

[32] Kohyama J. Obesity, insulin resistance, hypertension and sleep in the child. Int Child Health Nutrit 2012; 1: 23-7. https://doi.org/10.6000/1929-4247.2012.01.01.03

[33] Urrila AS, Artiges E, Massicotte J, et al. Sleep habits, academic performance, and the adolescent brain structure. Sci Rep 2017; 7: 41678. https://doi.org/10.1038/srep41678 
[34] Taki Y, Hashizume H, Thyreau B, et al. Sleep duration during weekdays affects hippocampal gray matter volume in healthy children. Neuroimage 2012; 60: 471-5. https://doi.org/10.1016/j.neuroimage.2011.11.072

[35] The Ministry of Education, Culture, Sports, Science and Technology. Results of research on relationship between lifestyle habits and self-reliance of children. [cited 2017 July 24]. Available from: http://www.mext.go.jp/a_menu/shougai/ katei/_icsFiles/afieldfile/2015/04/30/1357460_01_1_1.pdf(in Japanese)

[36] Doi Y, Ishihara K, Uchiyama M. Associations of chronotype with social jetlag and behavioral problems in preschool children. Chronobiol Int 2015; 32: 1101-8. https://doi.org/10.3109/07420528.2015.1063503
[37] Komada $\mathrm{Y}$, Breugelmans $\mathrm{R}$, Drake $\mathrm{CL}$, et al. Social jetlag affects subjective daytime sleepiness in school-aged children and adolescents: A study using the Japanese version of the Pediatric Daytime Sleepiness Scale (PDSS-J). Chronobiol Int 2016; 33: 1311-9.

https://doi.org/10.1080/07420528.2016.1213739

[38] Díaz-Morales JF, Escribano C. Social jetlag, academic achievement and cognitive performance: Understanding gender/sex differences. Chronobiol Int 2015; 32: 822-31. https://doi.org/10.3109/07420528.2015.1041599

[39] Levandovski R, Dantas G, Fernandes LC, et al. Depression scores associate with chronotype and social jet lag in a rural population. Chronobiol Int 2011; 28: 771-8. https://doi.org/10.3109/07420528.2011.602445

Received on 04-08-2017

(c) 2017 Jun Kohyama; Licensee Lifescience Global.

This is an open access article licensed under the terms of the Creative Commons Attribution Non-Commercial License (http://creativecommons.org/licenses/by-nc/3.0/) which permits unrestricted, non-commercial use, distribution and reproduction in any medium, provided the work is properly cited. 